University of South Carolina

Scholar Commons

1992

\title{
Comparing Electrochemical Impedance Spectroscopy Methods for Estimating the Degree of Delamination of Organic Coatings on Steel
}

S. A. McCluney

Texas A \& M University - College Station

S. N. Popova

Texas A \& M University - College Station

Branko N. Popov

University of South Carolina - Columbia, popov@engr.sc.edu

Ralph E. White

University of South Carolina - Columbia, white@cec.sc.edu

R. B. Griffin

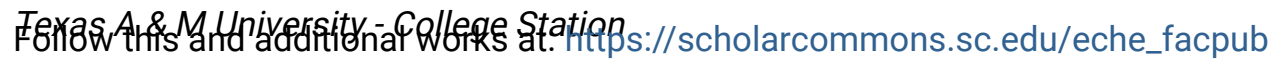

Part of the Chemical Engineering Commons

\section{Publication Info}

Journal of the Electrochemical Society, 1992, pages 1556-1560.

(c) The Electrochemical Society, Inc. 1992. All rights reserved. Except as provided under U.S. copyright law, this work may not be reproduced, resold, distributed, or modified without the express permission of The Electrochemical Society (ECS). The archival version of this work was published in the Journal of the Electrochemical Society.

http://www.electrochem.org/

DOI: $10.1149 / 1.2069454$

http://dx.doi.org/10.1149/1.2069454

This Article is brought to you by the Chemical Engineering, Department of at Scholar Commons. It has been accepted for inclusion in Faculty Publications by an authorized administrator of Scholar Commons. For more information, please contact digres@mailbox.sc.edu. 
$x \quad$ coordinate in direction of migration, $\mathrm{cm}$

$z \quad$ valence

$\delta$ cathode thickness, $\mathrm{cm}$

$\delta_{m} \quad$ matrix thickness, $\mathrm{cm}$

$\Delta \quad$ distance from cathode into matrix where $\mathrm{Ni}$ deposition occurs, $\mathrm{cm}$

$\theta$ fraction of cathode cross-sectional area occupied by electrolyte

$\boldsymbol{\theta}_{m} \quad$ matrix porosity

p electrolyte density $\mathrm{g} / \mathrm{cm}^{3}$

$\tau$ tortuosity

$\tau_{m} \quad$ matrix tortuosity

$\phi \quad$ electrolyte potential, volts

\section{REFERENCES}

1. W. M. Vogel, L. J. Bregoli, H. R. Kunz, and S. W. Smith, in "Molten Carbonate Fuel Cell Technology," R. J. Selman and T. D. Claar, Editors, PV 84-13, pp. 443451, The Electrochemical Society Softbound Proceedings Series, Pennington, NJ (01984).

2. K. Ota, T. Shinjo, and N. Kamiya, Denki Kagaku Oyubi Kogyo Butsuri Kayaku, 55, 323 (1987).

3. C. E. Baumgartner, J. Am. Ceram. Soc., 69, 162 (1986).

4. J. D. Doyon, T. Gilbert, G. Davies, and L. Paetsch, This Journal, 134, 3035 (1987).

5. C.-Y. Yuh and A. Pigeaud, Energy Research Corporation Final Report on DOE Contract No. DE-AC2186MC23264 (1989).

6. L. N. Lee and D. A. Shores, This Journal, 137, 859 (1990).

7. D. A. Shores, J. R. Selman, and E. T. Ong, Final Report on DOE Contract DE-AC21-86MC23263 (1989).

8. J. B. J. Veldhuis, R. C. Makkus, S. B. Van Der Molen, and G. H. J. Broers, Ber. Bunsenges. Phys. Chem., ECN-RX-90-027 (1990)
9. International Fuel Cells Topical Report on DOE Contract No. DC-AC21-87MC23270, FCR-10823 (1990).

10. H. R. Kunz, This Journal, 134, 105 (1987).

11. H. R. Kunz and L. A. Murphy, ibid., 135, 1124 (1988).

12. A. E. Merideth and C. W. Tobias in, "Advances in Electrochemistry and Electrochemical Engineering," Vol. 2, C. W. Tobias, Editor, p. 15, Interscience, New York (1966).

13. Final Report on Electric Power Research Project 1085-4, Prepared by Power Systems Division of United Technologies Corporation (1983).

14. G. J. Janz, C. B. Allen, N. P. Bansal, R. M. Murphy, and R.P. T. Tomkins, National Bureau of Standards, NSRDS-NBS 61, Part II (1979).

15. N. Kh. Tumanova, Ukrainskii Khimi. Z. (Russian ed.), 30, 648 (1964).

16. Final Technical Report on Gas Research Institute Contract No. 5081-344-0528, Power Systems Division of United Technologies Corporation (1985).

17. R. J. Remick, Final Report on Contract No. DE-AC2185MC22224 between the Institute of Gas Technology and the U.S. Department of Energy, DOE/MC/ 222224-2202 (1986)

18. T. Ogawa, H. Oozu, K. Murata, and T. Shirogami, Denki Kagaku, 58, 336 (1990).

19. H. R. Kunz, U. S. Pat. 4,591,538 (1986),

20. C. Yang, R. Takagi, K. Kawamura, and I. Okada, Electrochim. Acta, 32, 1607 (1987).

21. Final Report of Energy Research Corporation to the U. S. Department of Energy on Contracts DE-AC2176ET11304, DE-AC03-76ET11304, EY-76-CO3-1196, and E-(04-3) 1196 (1987).

22. H. R. Kunz and L. J. Bregoli, in "Molten Carbonate Fuel Cell Technology," J. R. Selman, D. A. Shores, H. C. Maru, and I. Uchida, Editors, PV 90-16, p. 157, The Electrochemical Society Softbound Proceedings Series, Pennington, NY (1990).

\title{
Comparing Electrochemical Impedance Spectroscopy Methods for Estimating the Degree of Delamination of Organic Coatings on Steel
}

\author{
S. A. McCluney, S. N. Popova, B. N. Popov, ${ }^{*}$ and R. E. White* \\ Center for Electrochemical Engineering, Department of Chemical Engineering, Texas A\&M University, \\ College Station, Texas 77843-3122

\section{R. B. Griffin} \\ Department of Mechanical Engineering, Texas A\&M University, College Station, Texas 77843-3122
}

\section{ABSTRACT}

Electrochemical impedance spectroscopy (EIS) was used to evaluate the degree of delamination of the epoxy primer Uniprime ED-4 $4^{1}$ electrocoated on phosphate-treated cold-rolled steel in $3.5 \% \mathrm{NaCl}$ exposed to air. Specimens with coating thicknesses of 20.3 and $20.8 \mu \mathrm{m}$ and surface areas of $78.5 \mathrm{~cm}^{2}$ were used. Coating parameters were obtained using a circuitanalog model. The area of delamination was estimated using several EIS parameters, including the pore resistance and the break point frequency. These values were compared to the corroded area determined visually. All methods considered exhibited a strong correlation over some or all of the range of exposure times.

Electrochemical impedance spectroscopy (EIS) has been used to predict the life of organic coatings used for corrosion protection (1). EIS has proven to be a powerful tool to obtain system specific parameters of coatings, especially for evaluating the early deviation of organic coatings from their initial capacitive behavior (1-4). An excellent paper by Kendig and Scully on this subject exists (5). It has been found that changes in the capacitance of the coating relate to the uptake of water $(6,7)$, while changes in

* Electrochemical Society Active Member.

1 PPG trademark. resistance have been analyzed in terms of the penetration by ionic species from the environment (8-12). According to Mansfeld et al. (13) various parameters obtained from impedance data, such as the break point frequency $f_{\mathrm{b}}$, can be used to estimate the degree of delamination of organic coatings and the extent of corrosion of the metals under these coatings. More recently, Hack and Scully (14) have demonstrated that the break point frequency can be used to determine the electrochemically active area of a coated sample, comparing the EIS results with American Society of Testing and Materials (ASTM, Philadelphia, PA) visual methods. 
It is the purpose of this paper to demonstrate the use of EIS to estimate the delaminated area of the epoxy primer Uniprime ED-4 electrocoated on phosphate-treated coldrolled steel using various coating parameters and to compare these areas to the observed corroded area. It is desirable to have an accurate means of estimating the corroded area, especially during the initial stages of corrosion when this area may not be visible. Such a technique would allow the early detection and quantification of corrosion, and would lead to predictions of the useful life of the coating. In this work, four parameters which are easily obtainable through EIS are used to predict the delaminated area at each exposure time, which is compared to a visually determined area. The different prediction methods are then compared to one another in order to choose the best method(s) to predict delaminated area.

Impedance data may be analyzed in two ways. In the graphical technique, coating parameters are determined directly from the impedance plots (Bode and complex plane plots). Alternatively, a model of the system may be fitted to the data to give the various parameters. The equivalent circuit (circuit-analog) model shown in Fig. 1 has been used to describe the ac behavior of polymer-coated electrodes (13). In the circuit-analog model, the resistances and capacitances are varied until the predicted ac behavior matches the experimental data as closely as possible. These electrical properties are then interpreted as the properties of the system: $C_{c}$ is the capacitance of the coating, $R_{\mathrm{po}}$ is the pore resistance of the coating, $C_{\mathrm{dl}}$ is the capacitance of the double layer at the metal substrate, $R_{\mathrm{p}}$ is the polarization resistance of the electrode, and $R_{\Omega}$ is the ohmic resistance of the electrolyte.

The pore resistance of a polymer coating has been related to the delaminated area, $A_{\mathrm{d}}$, according to the following (13-15)

$$
R_{\mathrm{po}}=\frac{R_{\mathrm{po}}^{\mathrm{o}}}{A_{\mathrm{d}}}
$$

where

$$
R_{\mathrm{po}}^{\mathrm{o}}=\rho d
$$

According to Haruyama et al. (15), the specific pore resistance, $R_{\mathrm{po}}^{\mathrm{o}}$, is assumed to be essentially constant during the delamination process, and the pore resistance decreases as the delaminated area increases. This implies that the corrosion process does not significantly change the properties of the overlying coating. The specific coating resistivity, $\rho$, represents the resistivity of a completely delaminated coating. This value may be estimated from long-term exposure data. Once it is obtained Eq. [1] above may be used to estimate delaminated area from the pore resistance according to the following

$$
A_{\mathrm{d}}=\frac{\rho d}{R_{\mathrm{po}}}
$$

Once the electrolyte has penetrated to the substrate, a double layer is formed beneath the coating with a capaci-

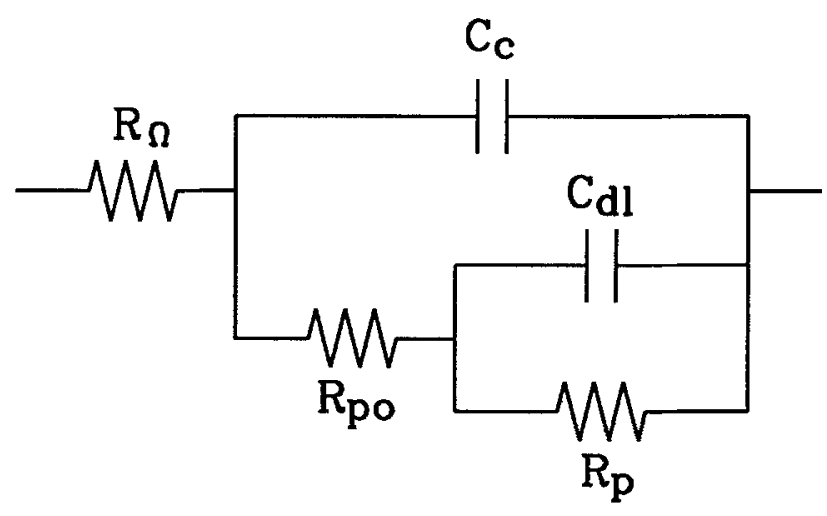

Fig. 1. The equivalent circuit used to model coated electrodes. tance proportional to the area of the substrate exposed to the electrolyte. The area exposed through the pores of the coating is assumed to be negligible compared to the disbonded area. Thus, the double layer capacitance is proportional to $A_{\mathrm{d}}$. The delaminated area may then be estimated from an experimental value of $C_{\mathrm{dl}}$ using the following $(13,15)$

$$
A_{\mathrm{d}}=\frac{C_{\mathrm{dl}}}{C_{\mathrm{dl}}^{\mathrm{o}}}
$$

The specific double layer capacitance, $C_{\mathrm{d} d}^{\circ}$, is that of the underlying substate. According to Juettner et al. (16), the experimental value of $A_{d}$ could be determined from Eq. [3] under the assumption that $C_{\mathrm{dl}}^{\mathrm{o}}$ is constant throughout the exposure time. In the above equation, it is assumed that the delaminated area is equal to the corroding area. This would not be true in the case of cathodic delamination in which the delaminated area may be much larger than the corroded area (17). In that case, the delaminated cathodic area will have a specific double layer capacitance which is different than the value for the corroding area. In this work, the value of $C_{d 1}^{o}$ is approximated by the double layer capacitance measured for an uncoated sample of the substrate. This implies that the environment at the corroding surface is not significantly altered by the presence of the coating. This would be true, for example, in the case where physical defects exist in the coating.

The polarization resistance (also known as the chargetransfer resistance) may also be used to estimate the delaminated area. Assuming once again that $A_{d}$ is equal to the corroding area, one obtains the following relationship (15)

$$
A_{\mathrm{d}}=\frac{R_{\mathrm{p}}^{\mathrm{o}}}{R_{\mathrm{p}}}
$$

The specific polarization resistance, $R_{\mathrm{p}}^{\mathrm{o}}$, is associated with the charge transfer behavior of the metal substrate, and can be estimated using the linear polarization of an uncoated sample of the substrate. The value of $R_{\mathrm{p}}^{\circ}$ is assumed to be constant, and it is again assumed that the corroding environment of a coated sample is similar to that of an uncoated sample.

A final method of estimating the delaminated area is that of Haruyama et al. (15). This technique uses the high frequency break point, $f_{b}$, which is defined as the frequency at which the phase angle equals $45^{\circ}$. According to the theory, the delaminated area may be determined as follows

$$
A_{\mathrm{d}}=\frac{f_{\mathrm{b}}}{f_{\mathrm{b}}^{\circ}} A
$$

The constant $f_{\mathrm{b}}^{\mathrm{o}}$ represents the break point frequency for a totally delaminated coating and depends only on coating parameters which are assumed to be constant

$$
f_{\mathrm{b}}^{\mathrm{o}}=\frac{1}{2 \pi \epsilon \epsilon^{\circ} \rho}
$$

The dielectric constant of the coating relative to that of free space, $\epsilon$, may be determined from a value of the coating capacitance, $C_{c}$, using the following relationship

$$
\epsilon=\frac{d}{\epsilon^{\circ} A} C_{c}
$$

The coating capacitance will change significantly during electrolyte absorption because the dielectric constant of water is approximately twenty times greater than that of a typical coating $\left(\epsilon_{\text {water }}=80, \epsilon \approx 4\right)$. The length of this period depends on the coating and the electrolyte used. The rate of change of the coating capacitance drops considerably as the electrolyte absorption nears completion.

\section{Experimental}

An electrochemical cell was designed in order to measure the coating characteristics using the EIS technique. 
The area of the working electrode was $78.5 \mathrm{~cm}^{2}$ so that the capacitance of the coating would be large enough to minimize measurement errors (5). The working electrode was a 4 in. by 12.6 in. panel of phosphate-treated cold-rolled steel with an epoxy primer (Uniprime ED-4) coating obtained by electrodeposition. The two samples had coating thicknesses of 20.3 and $20.8 \mu \mathrm{m}$. These were exposed under freely corroding conditions in $3.5 \% \mathrm{NaCl}$ solution open to the air and unstirred. A platinum gauze and a SCE served as the counter and reference electrodes, respectively.

EIS data were obtained using a PAR Model 5301 A twophase lock-in amplifier and a PAR Model 273 potentiostat. The data were stored and analyzed using PAR M378 software on an IBM PS/2. The frequency range of $1 \mathrm{mHz}$ to 100 $\mathrm{kHz}$ was applied with an ac voltage varying by $\pm 10 \mathrm{mV}$ about the open-circuit potential. Experimental values of $A_{\mathrm{c}}$ were determined visually according to ASTM D-610 and a modification of ASTM D-714 $(18,19)$.

\section{Results}

Figures 2 through 4 show representative samples of the observed behavior of the $20.3 \mu \mathrm{m}$ coating over a 69 day exposure to $3.5 \% \mathrm{NaCl}$ solution. The data are presented as Bode-magnitude plots (Fig. 2), Bode-phase plots (Fig. 3), and complex plane plots (Fig. 4), and are typical of coated electrode behavior. The data taken on day 2 for the $20.8 \mu \mathrm{m}$ sample were fitted to the circuit-analog model shown in Fig. 1 using Macdonald's complex nonlinear least squares algorithm, CNLS (20). A coating capacitance of $C_{c}=1.69 \times$ $10^{-8} \mathrm{~F}$ was obtained. Using this value and the coating thickness, the dielectric constant for this coating was calculated using Eq. [7] to be 5.06. This value is not significantly higher than the value expected for a dry coating. The electrolyte is expected to have a dielectric constant of approximately 80 , and absorption of a large quantity of electrolyte would increase $\epsilon$ accordingly. The low measured value of 5.06 indicates a relatively low amount of electrolyte absorption (5-7).

The Bode-phase plots of Fig. 3 show an initial shape with only one broad valley in the high-frequency range. This is indicative of only one distinct $R-C$ circuit, that of the porous coating $\left(R_{\mathrm{po}}\right.$ and $\left.\mathrm{C}_{\mathrm{c}}\right)$. By the tenth day of exposure in $3.5 \% \mathrm{NaCl}$ solution a second peak in the low-frequency range is seen, indicating that $R_{\mathrm{p}} C_{\mathrm{dl}}<<R_{\mathrm{po}} \mathrm{C}_{\mathrm{c}}$, so that the two time constants of the system are distinct. One can notice a shift of the first valley toward higher frequencies with increasing exposure time.

The time dependence of the complex plane plots is shown in Fig. 4. Initially, only the shape of one semicircle is seen (part of the data has been truncated in order to magnify the region near the origin). For a fully developed plot, we expect two semicircles because our coated specimen has two capacitances, one of the coating and one of the double layer on the substrate beneath the coating. After 10 days the beginning of the second semicircle is seen. The decrease of $R_{\mathrm{p}}$ may also be recognized by the decrease in the radius of the first (low frequency) semicircle. After 17 days, the second semicircle is almost developed.

Experimental values of $R_{\mathrm{pa}}, R_{\mathrm{p}}$, and $\mathrm{C}_{\mathrm{dl}}$, determined by fitting the data to the equivalent circuit of Fig. 1, are given in Table I and are shown in Fig. 5 as a function of exposure time. Measured values of $f_{\mathrm{b}}$ are also included in Table I. The data fit is not sensitive to the value of $R_{\Omega}$ since it is negligible compared to $R_{\mathrm{po}}$ and $R_{\mathrm{p}}$. Also, it is assumed that the majority of electrolyte absorption occurs during the first two days of exposure, so that the value of $C_{c}$ obtained after two days will be valid for the rest of the exposure period. Therefore, these two parameters, $R_{\Omega}=20 \Omega$ and $C_{c}=1.69 \times$ $10^{-8} \mathrm{~F}$, were held constant when fitting the data.

As seen in Table I and Fig. 5, the polarization resistance $R_{\mathrm{p}}$ decreases rapidly at the beginning of exposure but levels off afterward. The coating resistance, $R_{\text {po }}$, exhibits a similar behavior. The double-layer capacitance at the metal substrate, $C_{\mathrm{dl}}$, increases rapidly, but stabilizes after 10 to 15 days. The value of $R_{\mathrm{po}}$ after $1 \mathrm{~h}$ of exposure is greater than $1 \times 10^{6} \Omega$.

The delaminated area has been estimated according to Eq. [2] through [5]. In order to do this, a value for the speci-

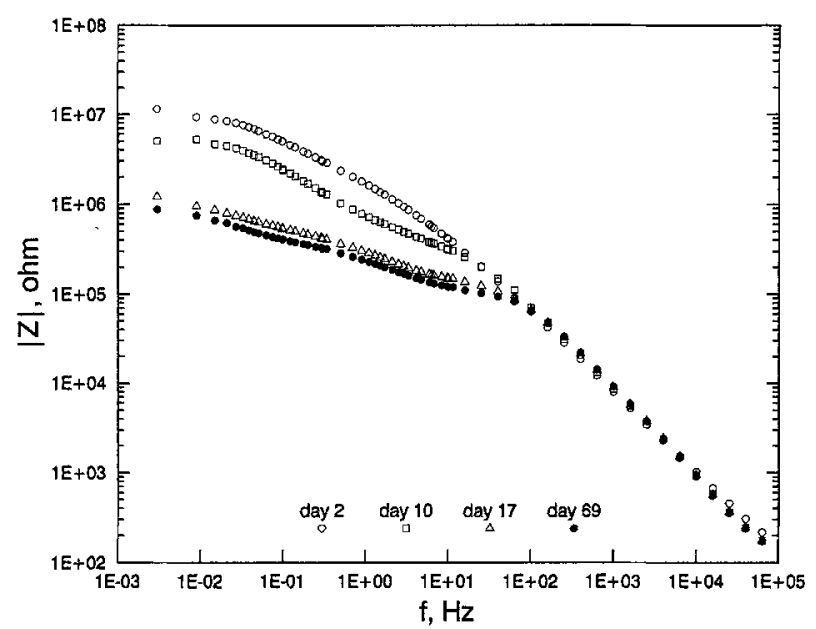

Fig. 2. Bode-magnitude plots obtained for exposure of the $20.3 \mu \mathrm{m}$ sample to $3.5 \% \mathrm{NaCl}$ at days $2,10,17$, and 69 .

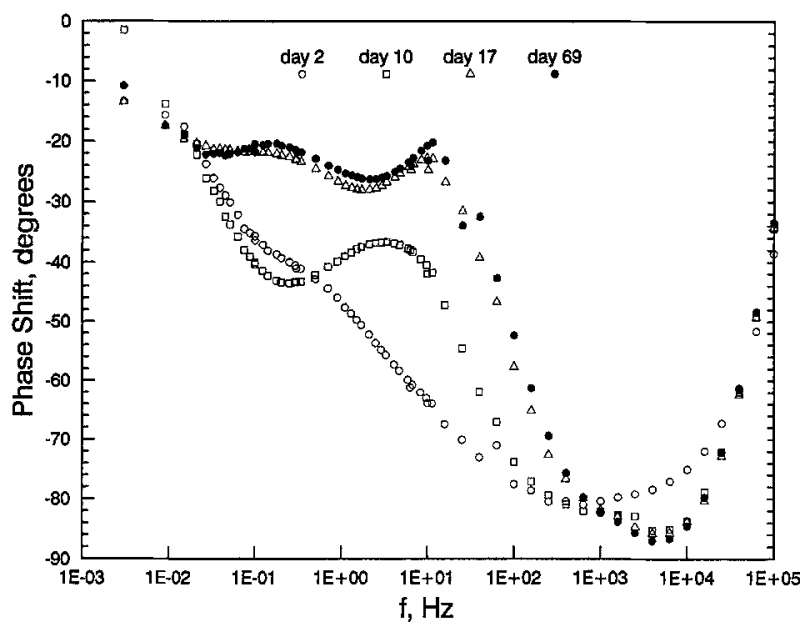

Fig. 3. Bode-phase plots obtained for exposure of the $20.3 \mu \mathrm{m}$ sample to $3.5 \% \mathrm{NaCl}$ solution at days $2,10,17$, and 69 .

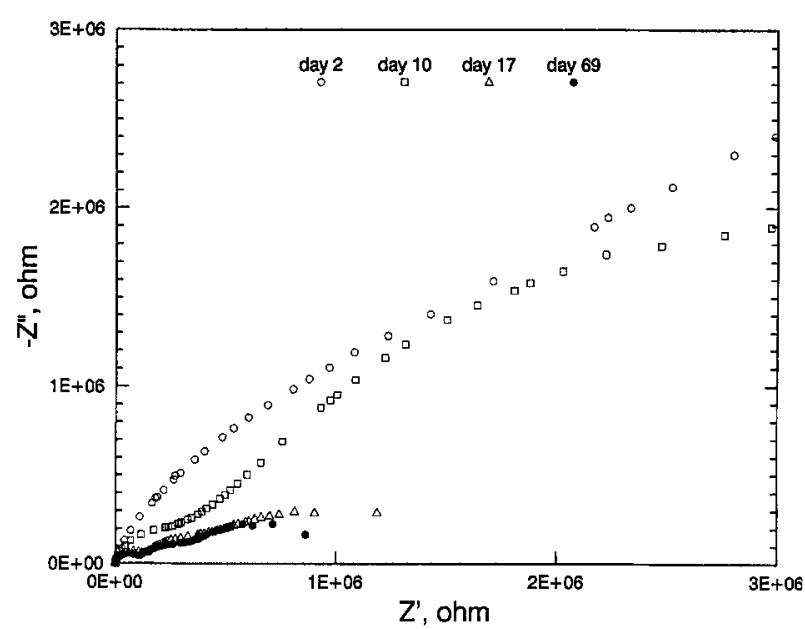

Fig. 4. Complex plane plots obtained for exposure of the $20.3 \mu \mathrm{m}$ sample to $3.5 \% \mathrm{NaCl}$ solution at days 2, 10, 17, and 69 .

fic resistivity of the coating, $\rho$, is required. This value was estimated by using Eq. [2] and data for 75 days of exposure to the electrolyte. The pore resistance, $R_{\mathrm{po}}$, was obtained using the circuit-analog method, and $A_{d}$ was estimated visually. Equation [2] was then used to obtain $\rho=7.15 \times 10^{6} \Omega$ $\mathrm{cm}$. This value is similar to that given by Mansfeld et al. (13) for polybutadiene coatings. The specific double-layer capacitance required in Eq. [3] was obtained by exposing 
Table I. Values of parameters for the $20.3 \mu \mathrm{m}$ sample, obtained by fitting the impedance

data (represented in Fig. 2-4), as a function of time.

\begin{tabular}{lllcr}
\hline $\begin{array}{l}\text { Exposure } \\
\text { (days) }\end{array}$ & $\begin{array}{c}R_{\mathrm{po}} \\
(\mathrm{M} \Omega)\end{array}$ & $\begin{array}{c}R_{\mathrm{p}} \\
(\mathrm{M} \Omega)\end{array}$ & $\begin{array}{c}\mathrm{C}_{\mathrm{dl}} \\
(\mathrm{nF})\end{array}$ & $\begin{array}{c}f_{\mathrm{b}} \\
(\mathrm{Hz})\end{array}$ \\
\hline $1 \mathrm{~h}$ & 1.40 & 6.75 & 78.5 & \\
2 & 1.27 & 6.50 & 245 & 2.31 \\
7 & 1.27 & 2.55 & 314 & 2.51 \\
11 & 0.764 & 1.91 & 440 & 9.74 \\
12 & 0.662 & 1.27 & 450 & 13.96 \\
13 & 0.369 & 1.21 & 1570 & 24.55 \\
14 & 0.255 & 1.18 & 1710 & 28.5 \\
15 & 0.136 & 1.15 & 1915 & 48.85 \\
23 & 0.127 & 1.12 & 2005 & 53.78 \\
27 & 0.115 & 0.726 & 2250 & 57.63 \\
41 & 0.115 & 0.510 & 2532 & 60.56 \\
60 & 0.102 & 0.344 & 2597 & 71.84 \\
69 & 0.0955 & 0.255 & 2650 & 87.27
\end{tabular}

an uncoated specimen of phosphate-treated cold-rolled steel to $3 \% \mathrm{NaCl}$ solution. The uncoated specimen was modeled as a simple Randles circuit (i.e., the circuit in Fig. 1 without the coating elements $R_{\mathrm{po}}$ and $C_{\mathrm{c}}$ ). The value of $C_{\mathrm{dl}}^{\mathrm{o}}=2.45 \times 10^{-5} \mathrm{~F} / \mathrm{cm}^{2}$ was obtained. The specific polarization resistance used in Eq. [4] was determined for the same uncoated sample by linear polarization. Its value was found to be $R_{\mathrm{p}}^{\circ}=5.23 \times 10^{4} \Omega \mathrm{cm}^{2}$. Finally, as mentioned above, the dielectric constant of the coating relative to that of free space was found to be 5.06, using Eq. [7] and a value of $C_{c}$ obtained after 2 days of exposure of the $20.8 \mu \mathrm{m}$ sample. This parameter is necessary in order to use Eq. [5] to estimate the delaminated area. The constant $f_{\mathrm{b}}^{o}$ was calculated to be $4.97 \times 10^{4} \mathrm{~Hz}$ by using the above parameters and Eq. [6].

\section{Discussion}

Values for $R_{\mathrm{po}}, C_{\mathrm{dl}}$, and $R_{\mathrm{p}}$ were obtained by fitting the data represented in Fig. 2 through 4 and values for $f_{b}$ were obtained by hand from the same data. The delaminated areas determined using the above values with Eq. [2] through [5], and the values of $A_{d}$ observed visually, are shown in Table II. Figure 6 shows the ratio of predicted $A_{\mathrm{d}}$ to observed $A_{d}$ for each method considered. Considering the inaccuracies associated with corrosion measurements, the agreement is good for exposure times greater than 20 days. Each method predicts values of $A_{\mathrm{d}}$ which are higher than the observed values over most of the exposure range. This difference is greatest during the initial exposure period (approximately two weeks). The polarization resistance exhibits the highest initial deviation, and the ratio $A_{\mathrm{d}}\left(R_{\mathrm{p}}\right) / A_{\mathrm{d}}$ (observed) does not approach a constant value. Its value drops below 1 on the 23rd day of exposure and climbs continuously to a value of 1.6 by day 69 . The pore resistance also starts quite high, but $A_{\mathrm{d}}\left(R_{\mathrm{po}}\right) / A_{\mathrm{d}}$ (observed)

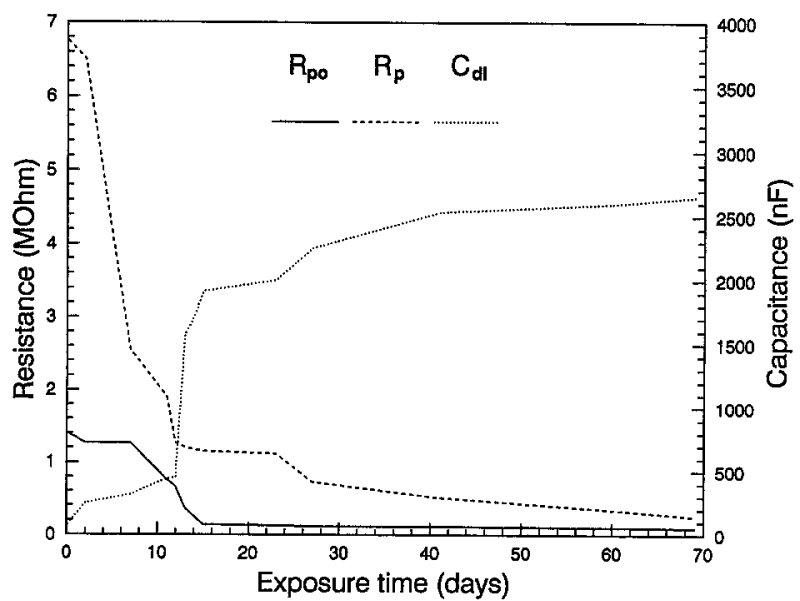

Fig. 5. Experimental parameters of the $\mathbf{2 0 . 3} \mu \mathrm{m}$ sample, determined by fitting the equivalent circuit model of Fig. 1 to the data, shown as a function of time.
Table II. Delaminated areas calculated from Eq. [2]-[5] and observed for the $20.3 \mu \mathrm{m}$ sample as a function of exposure time.

\begin{tabular}{lcllll}
\hline $\begin{array}{l}\text { Exposure } \\
\text { time } \\
\text { (days) }\end{array}$ & $\begin{array}{c}A_{\mathrm{d}}\left(\mathrm{cm}^{2}\right) \\
\text { from } R_{\mathrm{po}} \\
\text { (Eq. [2] }\end{array}$ & $\begin{array}{l}A_{\mathrm{d}}\left(\mathrm{cm}^{2}\right) \\
\text { from } C_{\mathrm{dl}} \text { (Eq. [3] }\end{array}$ & $\begin{array}{c}A_{\mathrm{d}}\left(\mathrm{cm}^{2}\right) \\
\text { from } R_{\mathrm{f}} \\
\text { (Eq. [4]) }\end{array}$ & $\begin{array}{c}A_{\mathrm{d}}\left(\mathrm{cm}^{2}\right) \\
\text { from } f_{\mathrm{b}} \\
\text { (Eq. [5]) }\end{array}$ & $\begin{array}{c}A_{\mathrm{d}}\left(\mathrm{cm}^{2}\right) \\
\text { (observed) }\end{array}$ \\
\hline 2 & 0.011 & 0.010 & 0.008 & 0.0036 & \\
7 & 0.011 & 0.013 & 0.021 & 0.004 & 0.003 \\
11 & 0.019 & 0.018 & 0.027 & 0.015 & 0.01 \\
12 & 0.022 & 0.018 & 0.041 & 0.022 & \\
13 & 0.039 & 0.064 & 0.043 & 0.039 & 0.024 \\
14 & 0.057 & 0.070 & 0.044 & 0.045 & \\
15 & 0.107 & 0.078 & 0.045 & 0.077 & \\
23 & 0.114 & 0.082 & 0.047 & 0.085 & 0.071 \\
27 & 0.126 & 0.092 & 0.072 & 0.091 & 0.079 \\
41 & 0.126 & 0.103 & 0.103 & 0.096 & 0.082 \\
60 & 0.142 & 0.106 & 0.152 & 0.11 & 0.10 \\
69 & 0.152 & 0.108 & 0.205 & 0.14 & 0.13 \\
& & & & &
\end{tabular}

is almost constant after day 12 , dropping slightly near the end of the exposure range. Thus, although its prediction is consistently high, the pore resistance does predict values of $A_{\mathrm{d}}$ which are nearly proportional to the observed corroded area. The double layer capacitance yields much closer values of $A_{d}$, but the correlation is not as strong, with $A_{\mathrm{d}}\left(C_{\mathrm{d} 1}\right) / A_{\mathrm{d}}$ (observed) dropping steadily after 40 days of exposure. The best predictions of $A_{d}$ were obtained using the break point frequency. During the initial exposure period, the predicted delaminated areas are much closer to the observed areas using this method. The value of $A_{d}\left(f_{b}\right) / A_{d}$ (observed) is closest to unity over most of the exposure range and is more nearly constant than that obtained using the double layer capacitance.

Every technique considered demonstrates strong qualitative agreement between predicted and observed delaminated area. At least some of the error can be attributed to the inaccuracies involved in visually determining the corroded area. In fact, one would expect that the actual delaminated area would be slightly larger than the visibly corroded area, and therefore closer to the predicted areas. It is also possible that some error resulted from holding $C_{c}$ constant while fitting the data. A more accurate method would be to fit $C_{c}$ for each exposure time along with the other parameters of the equivalent circuit.

The break-point frequency method, when applicable, offers several advantages over the other methods. First, it is not necessary to fit the entire data set to an equivalent circuit model in order to estimate $f_{\mathrm{b}}$. Second, $f_{\mathrm{b}}$ can be determined from high-frequency data which can be obtained quickly. Therefore, an estimate of delaminated area can be found quite rapidly using $f_{\mathrm{b}}$. On the other hand, this method does not make use of the full set of data. Because of this, it is possible that one of the other methods might be more appropriate in certain cases. Also, the break point frequency method alone does not provide any information beyond an estimate of the delaminated area.

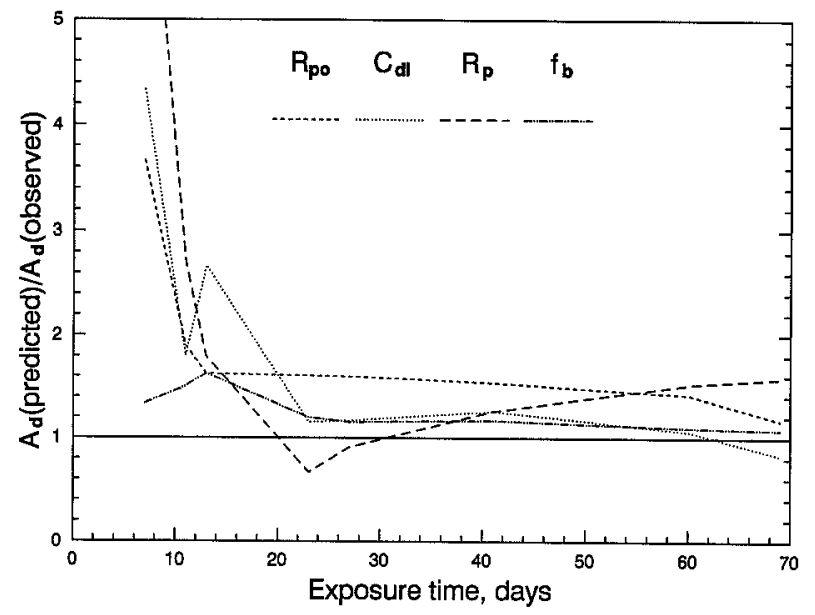

Fig. 6. Ratio of predicted $A_{d}$ to observed $A_{d}$ for each method considered over the range of exposure times. 
In conclusion, EIS provides several methods to estimate the delaminated area of an organic coating on a phosphatetreated steel substrate. Each method considered showed good qualitative agreement with observation over some portion of the exposure range. The break point frequency and the double-layer capacitance provided the estimates of $A_{d}$ which were closest to the visually determined corroded area, with the best correlation obtained using the break point frequency. These results are in agreement with those found by Hack and Scully (14).

\section{Acknowledgments}

The authors are grateful for the support of this work by the Dow Chemical Company and the National Science Foundation through the Offshore Technology Research Center.

Manuscript submitted June 20, 1991; revised manuscript received Jan. 29, 1992.

Texas A\&M University assisted in meeting the publication costs of this article.

\section{LIST OF SYMBOLS}

A total specimen area, $\mathrm{cm}^{2}$

$A_{\mathrm{d}} \quad$ defect (delamination) area, $\mathrm{cm}^{2}$

$C_{c}$ coating capacitance, $\mathbf{F}$

$\mathrm{C}_{\mathrm{c}}^{\mathrm{O}} \quad$ specific coating capacitance, $\mathrm{F} / \mathrm{cm}^{2}$

$C_{d l}$ capacitance of the double layer, $F$

$\mathrm{C}_{\mathrm{dl}}^{\mathrm{o}} \quad$ specific double-layer capacitance of the substrate, $\mathrm{F} / \mathrm{cm}^{2}$

d coating thickness, $\mathrm{cm}$

$f$ frequency, $\mathrm{Hz}$

$f_{\mathrm{b}} \quad$ break-point frequency, $\mathrm{Hz}$

$f_{\mathrm{b}}^{\mathrm{o}}$ break-point frequency for complete delamination, $\mathrm{Hz}$

$R_{\mathrm{p}} \quad$ polarization resistance, $\Omega$

$R_{\mathrm{p}}^{\mathrm{o}} \quad$ specific polarization resistance of the substrate, $\Omega$ $\mathrm{cm}^{2}$

$R_{\text {po }} \quad$ pore resistance, $\mathbf{\Omega}$

$R_{\mathrm{po}}^{\mathrm{o}} \quad$ specific pore resistance, $\Omega \mathrm{cm}^{2}$

$R_{\Omega} \quad$ solution resistance, $\Omega$

$Z$ coating impedance, $\Omega \mathrm{cm}^{2}$

$Z^{\prime} \quad$ real component of impedance, $\Omega \mathrm{cm}^{2}$

$Z^{\prime \prime} \quad$ imaginary component of impedance, $\Omega \mathrm{cm}^{2}$ $\epsilon$ dielectric constant of a coating relative to that of free space

$\boldsymbol{\epsilon}_{\mathrm{water}}$ dielectric constant of water relative to that of free space

$\epsilon^{0} \quad$ dielectric constant for free space $=8.85 \times 10^{-14}$, $\mathrm{F} / \mathrm{cm}$

$\rho$ specific coating resistivity for complete delamination, $\Omega \mathrm{cm}$

\section{REFERENCES}

1. M. W. Kendig, F. Mansfeld, and S. Tsai, Corros. Sci., 23, 317 (1983).

2. F. Mansfeld, M. W. Kendig, and S. Tsai, Corrosion, 38, 478 (1982).

3. W. J. Lorenz and F. Mansfeld, Corros. Sci., 21, 647 (1984).

4. F. Mansfeld, Corrosion, 44, 856 (1988)

5. M. W. Kendig and J. R. Scully, ibid., 46, 22 (1990).

6. J. R. Scully, This Journal, 136, 4 (1989).

7. H. Leidheiser, Jr., R. D. Granata, and S. Turosy, Corrosion, 43, 296 (1986).

8. W. S. Tait, J. Coat. Technol., 46, 768 (1989).

9. H. Leidheiser, Jr., Corrosion, 39, 189 (1983).

10. J. Titz, G. H. Wagne, and H. Spahn, ibid., 46, 3 (1990).

11. R. Oltra and M. Kedam, Corros. Sci., 28, 1 (1988).

12. J. Lorenz, Corrosion, 46, 3 (1990)

13. F. Mansfeld, C. H. Tsai, and H. Shih, in "Advances in Corrosion Protection by Organic Coatings," D. Scantlebury and M. Kendig, Editors, PV 89-13, p. 228, The Electrochemical Society Softbound Proceedings, Pennington, NJ (1989).

14. H. P. Hack and J. R. Scully, This Journal, 138, 33 (1991).

15. S. Haruyama, M. Asari, and T. Tsuru, in "Corrosion Protection by Organic Coatings," M. W. Kendig and H. Leidheiser, Jr., Editors, PV 87-2, p. 197, The Electrochemical Society Softbound Proceedings Series, Pennington, NJ (1986).

16. K. Juettner, W. J. Lorenz, and F. Mansfeld, "Corrosion/89," Paper No. 135, NACE (1989).

17. G. N. Murray and P. G. Moran, Corrosion, 45, No. 134 (1989).

18. "1986 ASTM Annual Book of Standards," Vol. 06-07, p. 96, ASTM, Philadelphia, PA (1986).

19. Ibid., p. 124

20. J. R. Macdonald, J. Electroanal. Chem, ,223, 25 (1987).

\title{
Corrosion Mechanism of Sputter-Deposited TbFe Thin Films in Aqueous Environment
}

\author{
Noboru Akao and Katsuhisa Sugimoto* \\ Department of Metallurgy, Faculty of Engineering, Tohoku University, Sendai 980, Japan
}

\section{ABSTRACT}

The corrosion mechanism of sputter-deposited $\mathrm{TbFe}$ thin films for magneto-optical recording material was investigated using electrochemical methods in aqueous environment with and without $\mathrm{Cl}^{-}$ions. TbFe thin films with varying composition prepared by an ion beam sputtering method were used as specimens. TbFe tape alloys made by the rapid quench method of melting alloys were also used for comparison. In an acid buffer solution without $\mathrm{Cl}^{-}$ions, the corrosion rate of the $\mathrm{TbFe}$ thin films and tape alloys decreased with increasing $\mathrm{Tb}$ content. In this solution, passive films composed of Tb oxide or hydroxide were formed on both the TbFe thin films and tapes and the selective dissolution of Fe through the passive films occurred. In neutral solutions with $\mathrm{Cl}^{-}$ions, pitting corrosion occurred on both the TbFe thin films and tapes. The stoichiometric dissolution of the substrate at pitted sites and the selective dissolution through the passive films at nonpitted sites take place in these solutions.

Rare earth-transition metal (RE-TM) thin films represented by sputter-deposited $\mathrm{TbFe}$ thin films have been intensively investigated for erasable magneto-optical recording materials, because they have high coercivity, large Kerr rotation angle, suitably low Curie temperature, and large perpendicular uniaxial anisotropy $(1,2)$. RE-TM thin films used for magneto-optical recording materials, however, suffer from high-temperature oxidation by the irradi-

\footnotetext{
* Electrochemical Society Active Member
}

ation of the reading-out Laser beam (3-5) and corrosion by humidity in the environment $(6,7)$. As a result, the degradation of magnetic properties proceeds rapidly and error rates in reading-out increase (8). Among these problems, corrosion due to aqueous solutions from the environment is serious because it progresses quickly at room temperature.

Many studies have been reported on the corrosion of RE-TM thin films in aqueous solutions; the measurement of corrosion rates by using light transmittance through the 